\section{CHARACTERISTICS AND DISTRIBUTION OF POLYPS FOUND IN BOWEL CANCER SCREENING COLONOSCOPY}

W Lai, M Fung, J Vatish, R Pullan, M Feeney Torbay Endoscopy Unit, Torbay Hospital, Torquay, UK

\subsection{6/gutjnl-2013-305143.112}

Introduction Bowel Cancer Screening Programme (BCSP) in the UK achieved nationwide coverage in 20101. We collected data from a local endoscopy unit that performs bowel cancer screening colonoscopy between 2010 and 2011.

Aims/Background This audit aims to look at the characteristics and distribution of polyps found in screening as well as surveillance colonoscopies performed under the BCSP.

Method Patients aged between 60 and 75 who underwent bowel cancer screening colonoscopy (first and surveillance) in Torbay endoscopy unit from January 2010 to December 2011 were identified from the BCSP database (Oracle BI Interactive Dashboards). Endoscopy reports were drawn from Scorpio (C) reporting system and corresponding histology results using Cyberlab $\mathbb{C}$ integrated pathology system.

Results 887 procedures were performed in the 2 year period. 794 polyps were found in 354 procedures, giving a polyp detection rate of $39.9 \%$ in this series. Of which $6 \%$ contained focus/ were of high grade dysplasia. Majority of polyps was found in the sigmoid colon (40.8\%) and rectum (13.5\%). 669 polyps

\begin{tabular}{llll} 
Table 1 & & \\
\hline Age Group & $\begin{array}{l}\text { Tubular } \\
\text { Adenoma }\end{array}$ & $\begin{array}{l}\text { Tubulovillous } \\
\text { Adenoma }\end{array}$ & $\begin{array}{l}\text { Hyperplastic } \\
\text { Polyp }\end{array}$ \\
\hline Overall $(n=699)$ & $362(51.8 \%)$ & $243(34.7 \%)$ & $53(7.6 \%)$ \\
$60-65(n=276)$ & $131(47.4 \%)$ & $99(35.9 \%)$ & $28(10.1 \%)$ \\
$66-70(n=213)$ & $111(52.1 \%)$ & $75(35.2 \%)$ & $15(7 \%)$ \\
$>70(n=210)$ & $120(57 \%)$ & $69(32.9 \%)$ & $10(4.8 \%)$ \\
\hline$n=$ the no. of polyps found in each age group.
\end{tabular}

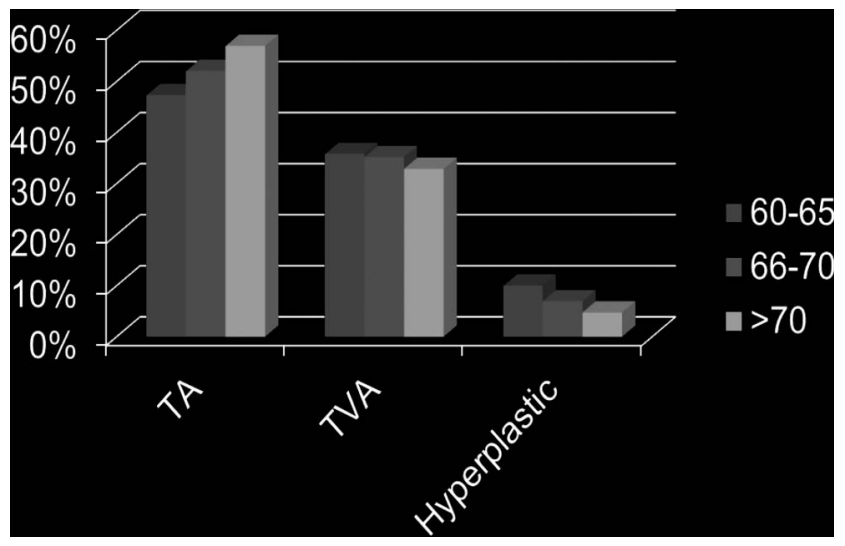

Figure 1

had histology results, of which $51.8 \%$ were Tubular adenomas, $34.7 \%$ Tubulovillous adenomas and 7.6\% Hyperplastic polyps. There was a $9.6 \%$ increase $(95 \%$ CI $18.5 \%-0.7 \%)$ in the proportion of Tubular adenomas in the over 70 s compare with the 60-65 age group (57\% vs. $47.4 \%$ ) (Table 1$)$. There was also an apparent shift from Hyperplastic polyps and Tubulovillous adenoma to Tubular adenoma with increasing age (Figure 1).

Conclusion The most common benign polyp found was Tubular adenomas, and more common amongst the elderly (statistically significant), but further study such as a national BCSP evaluation is needed. 